\title{
Siete memoriales españoles en defensa del arte de la pintura, eds. Antonio Sánchez Jiménez y Adrián J. Sáez, con estudios y notas complementarias de Juan Luis González García y Antonio Urquízar Herrera, Madrid / Frankfurt, Iberoamericana / Vervuert, 2018, 248 pp. ISBN: 978-84-8489-077-5
}

\section{Natalia Fernández Rodríguez}

Universidad Complutense de Madrid ESPAÑA

nferna08@ucm.es

[Hipogrifo, (issn: 2328-1308), 8.2, 2020, pp. 879-881]

Recibido: 18-06-2020 / Aceptado: 02-07-2020

DOI: http://dx.doi.org/10.13035/H.2020.08.02.53

Los vínculos múltiples entre lo literario y lo pictórico no han pasado desapercibidos para los especialistas en la literatura española del Siglo de Oro que, con frecuencia creciente en los últimos años, han transitado esos pasadizos interartísticos desde planteamientos diversos. Más allá del problema estético, la relación entre literatura y pintura en la España del Siglo de Oro posee una determinante dimensión socioeconómica concretada en reivindicación del carácter ingenuo, esto es liberal, del arte de la pintura y de la exención del pago de la alcabala a los pintores. Cuando en 1626 se inició un proceso judicial entre los pintores y el fiscal del rey para solicitar precisamente la liberación del tributo, los escritores se posicionaron de forma muy activa a favor de los artistas, de tal modo que los argumentos estéticos -entre los que nunca faltó la comparación con la poesía- y los legales terminaron imbricándose. 
Antonio Sánchez Jiménez y Adrián J. Sáez se encargan de editar un documento esencial para comprender esa problemática social del artista en el Siglo de Oro y la convencida implicación de los poetas en la defensa de la pintura y sus cultivadores. Se trata del Memorial informatorio por los pintores en el pleito que tratan con el señor fiscal de su majestad en el Real Consejo de Hacienda sobre la exención del arte de la pintura (1629). Hasta la fecha, nadie había abordado aún la tarea de poner a disposición de la comunidad investigadora una versión filológicamente depurada y científicamente anotada de esta «miscelánea de pareceres» (p. 29) citada de forma reiterada por los especialistas. El presente volumen es, por tanto y por encima de todo lo demás, imprescindible: los investigadores necesitaban, literalmente, este trabajo. Y que lo hayan llevado a cabo dos de los más reconocidos especialistas en las conexiones literatura-pintura en la España áurea garantiza su rigor y calidad. Algunos de los títulos esenciales sobre esta problemática se deben justamente a ellos como es el caso de El pincel y el Fénix: pintura y literatura en la obra de Lope de Vega (Sánchez Jiménez, Madrid/Frankfurt, Iberoamericana-Vervuert, 2011) o El ingenio del arte: la pintura en la poesía de Quevedo (Sáez, Madrid, Visor Libros, 2015), por citar únicamente dos ejemplos.

Desde el arranque mismo del trabajo se explica, además, que «el texto del Memorial se centra en problemas muy concretos que atañen no solamente a la filología y la historia de la literatura, sino principalmente a la historia del arte, y por ello nuestro equipo incluye también dos expertos en la materia» (p. 12). Juan Luis González García y Antonio Urquízar Herrera se encargan de parte del estudio introductorio, donde se contextualiza pormenorizadamente la problemática desde el punto de vista histórico, jurídico y social. La colaboración entre filólogos e historiadores del arte permite ofrecer una visión integral del problema, y lleva a la práctica una interdisciplinariedad que se ha venido reclamando en los últimos años y que se revela casi ineludible en las humanidades. Coincidimos, por tanto, con los editores en su deseo de que futuros estudiosos se animen a proseguir este camino (p. 13).

La introducción ocupa un total de 65 páginas, si excluimos los dos apartados finales sobre cuestiones ecdóticas y bibliográficas. El análisis histórico-literario se divide en cuatro bloques: «La querelle de la pintura» (pp. 11-13), «La ingenuidad de la pintura y la teoría jurídica y social de los clásicos» (pp. 15-27), «La andanada del Memorial» (pp. 29-48) y «De 'siete Cicerones españoles' y un predicador indiano» (pp. 49-65). En su conjunto, constituye una síntesis impecable del contexto, contenido y función del Memorial, desde las cuestiones más generales sobre las circunstancias que explicaron la polémica hasta las raíces clásicas - retóricas, estéticas y filosóficas - que laten en la composición del texto. El tercer apartado, «La andanada del Memorial», a cargo de Sánchez Jiménez y Sáez, se ocupa en detalle del texto en sí, que definen como «un argumento colectivo que trata de presentar una defensa integral y total» (p. 31). En este sentido, se desmenuzan los argumentos aportados por cada uno de los siete participantes: Rodríguez de León, Lope de Vega - cuya implicación en la causa de la pintura se resalta especialmente-, Valdivielso, Vanderhamen, Jáuregui, Butrón y León Pinelo. En apenas veinte páginas se ofrece una síntesis completa de los argumentos -estéticos, filosóficos, 
históricos, religiosos, legales - que se adujeron en defensa de los pintores. Quedan claros así no solo el contenido del Memorial sino esas intersecciones constantes entre planteamientos de diversa naturaleza que caracterizaron la polémica.

Respecto a la edición del texto, los criterios se especifican en el apartado quinto de la introducción (pp. 68-77). Se sigue la edición prínceps de 1629 según el ejemplar conservado en la BNE con signatura BA/4138, y se comentan brevemente los cambios introducidos en la versión que sigue a los Diálogos de Vicente Carducho, de 1633. Consideramos muy adecuada la decisión de los editores, que alertan de que estos cambios se concretan, incluso, en la reescritura de algunos pasajes. Desde el punto de vista ecdótico, no se habría justificado emplearlo como texto base por más que, en no pocas ocasiones, sea justamente la versión de Carducho la que aparece citada en los estudios actuales sobre el tema, tal vez por su mayor accesibilidad. Una prueba más, en definitiva, de la necesidad de llevar a cabo la edición del Memorial de 1629. El apartado de variantes (pp. 209-220) no indica ninguna enmienda discutible al texto de la prínceps. Las notas al pie se limitan a especificar las fuentes o a aclarar el sentido de algunas referencias. Se trata de intervenciones pertinentes y, en todo caso, muy concisas que nunca entorpecen la lectura.

Cierran el volumen dos apéndices. El primero (pp. 223-233) incluye la edición del texto de Valdivielso tal como fue reescrito para los Diálogos de Carducho. Las sustanciales diferencias respecto a la primera versión justifican, sin duda, su adición. En segundo lugar, se edita también la silva lopesca «Si cuanto fue posible en lo imposible», incluida también en los Diálogos y que, según los editores, «es tal vez la más completa apología de la pintura que compuso el Fénix» (p. 235). El poema va precedido de un breve pero interesantísimo estudio que lo contextualiza dentro de la obra de Carducho, deteniéndose incluso en el comentario del grabado Ars magna naturae renovat omnia al que acompaña la silva. Los poemas incluidos en los Diálogos han sido objeto de interés para uno de los editores, Adrián J. Sáez, que los estudia en otro artículo en curso de publicación en la revista Edad de Oro.

Es este, en definitiva, por la relevancia de su contenido y por el esfuerzo de concisión de sus autores, uno de esos trabajos llamados a convertirse en obras de referencia para los investigadores de la literatura española del Siglo de Oro y, en concreto, para los interesados en esos vínculos apasionantes y complejos entre la poesía y la pintura, los poetas y los pintores. 